\title{
Control Strategies for Vehicle Suspension System Featuring Magnetorheological (MR) Damper
}

\author{
Min-Sang Seong ${ }^{1}$, Seung-Bok Choi ${ }^{1}$ and Kum-Gil Sung 2 \\ ${ }^{1}$ Inha University \\ ${ }^{2}$ Yeungnam College of Science and Technology \\ Korea
}

\section{Introduction}

Vehicle suspension is used to attenuate unwanted vibrations from various road conditions. So far, three types of suspension system have been proposed and successfully implemented; passive, active and semiactive. Though the passive suspension system featuring oil damper provides design simplicity and cost-effectiveness, performance limitations are inevitable due to the lack of damping force controllability. On the other hand, the active suspension system can provides high control performance in wide frequency range. However, this type may require high power sources, many sensors and complex actuators such as servovalves. Consequently, one way to resolve these requirements of the active suspension system is to adopt the semiactive suspension system. The semiactive suspension system offers a desirable performance generally enhanced in the active mode without requiring large power sources and expensive hardware.

One of very attractive and effective semiactive vehicle suspension systems is to utilize magnetorheological (MR) fluid. MR fluids are currently being studied and implemented as actuating fluids for valve systems, shock absorbers, engine mounts, haptic systems, structure damper, and other control systems. The rheological properties of MR fluids are reversibly and instantaneously changed by applying a magnetic field to the fluid domain. Recently, a very attractive and effective semi-active suspension system featuring MR fluids has been researched widely. Carlson et al., 1996 proposed a commercially available MR damper which is applicable to on-and-off-highway vehicle suspension system. They experimentally demonstrated that sufficient levels of damping force and also superior control capability of the damping force by applying control magnetic field. Spencer Jr. et al., 1997 proposed dynamic model for the prediction of damping force of a MR damper. They compared the measured damping forces with the predicted ones in time domain. Kamath et al., 1998 proposed a semi-active MR lag mode damper. They proposed dynamic model and verified its validity by comparing the predicted damping force with the measured one. Yu et al., 2006 evaluated the effective performance of the MR suspension system by road testing. Guo \& Hu, 2005 proposed nonlinear stiffness model of a MR damper. They proposed nonlinear stiffness model and verified it using simulation and experiment. Du et al., 2005 
proposed H-infinity control algorithm for vehicle MR damper and verified its effectiveness using simulation. Shen et al., 2007 proposed load-levelling suspension with a magnetorheological damper. Pranoto et al., 2005 proposed 2DOF-type rotary MR damper and verified its efficiencies. Ok et al., 2007 proposed cable-stayed bridges using MR dampers and verified its effectiveness using semi-active fuzzy control algorithm. Choi et al., 2001 manufactured an MR damper for a passenger vehicle and presented a hysteresis model for predicting the field-dependent damping force. Hong et al., 2008 derived a nondimensional Bingham model for MR damper and verified its effectiveness through experimental investigation. Yu et al., 2009 developed human simulated intelligent control algorithm and successfully applied it to vibration control of vehicle suspension featuring MR dampers. Seong et al., 2009 proposed hysteretic compensator of MR damper. They developed nonlinear Preisach hysteresis model and hysteretic compensator and demonstrated its damping force control performance.

As is evident from the previous research work, MR damper is very effective solution for vibration control of vehicle suspension system. So in this chapter, we formulate various vibration control strategies for vibration control of MR suspension system and evaluate their control performances. In order to achieve this goal, material characteristics of MR fluid are explained. Then the MR damper for vehicle suspension system is designed, modelled and manufactured. The characteristics of manufactured MR damper are experimentally evaluated. For vibration control, the quarter vehicle suspension system featuring MR damper is modelled and constructed. Then, various vibration control strategies such as skyhook control, PID control, LQG control, $\mathrm{H}_{\infty}$ control, Sliding mode control, moving sliding mode control and fuzzy moving sliding mode control are formulated. Finally, control performances of the proposed control algorithms are experimentally evaluated and compared.

\section{Suspension modelling}

\subsection{MR fluid}

Since Jacob Rabinow discovered MR fluid in the late 1940s, of which yield stress and viscosity varies in the presence of magnetic field, various applications using MR fluid have been developed such as shock absorbers, clutches, engine mounts, haptic devices and structure dampers, etc (Kim et al., 2002). Physical property changes of MR fluid are resulted from the chain-like structures between paramagnetic MR particles in the low permeability solvent. At the normal condition, MR fluid shows the isotropic Newtonian behavior because the MR particles move freely as shown in Fig. 1 (a). However, when the magnetic field applied to the MR fluid, MR fluid shows the anisotropic Bingham behavior and resist to flow or external shear force because the MR particles make a chain structure as shown in Fig. 1 (b). From this property, force or torque of application devices can be easily controlled by the intensity of the magnetic field.

\subsection{MR damper}

The schematic configuration of the cylindrical type MR damper proposed in this work is shown in Fig. 2. The MR damper is composed of the piston, cylinder and gas chamber. The floating piston between the cylinder and the gas chamber is also used in order to compensate for the volume induced by the motion of the piston. Also the gas chamber 


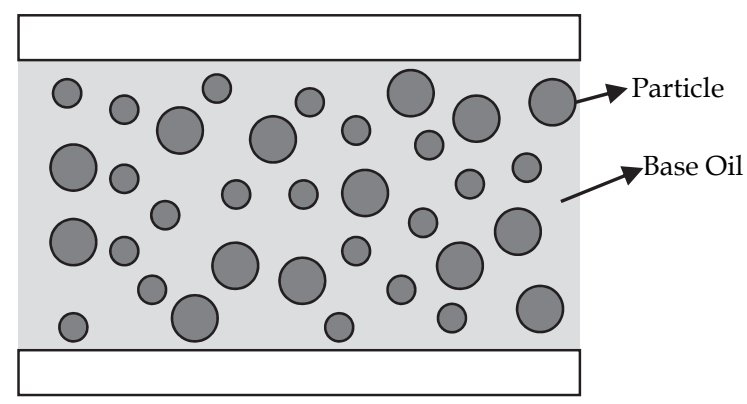

(a) no magnetic field applied

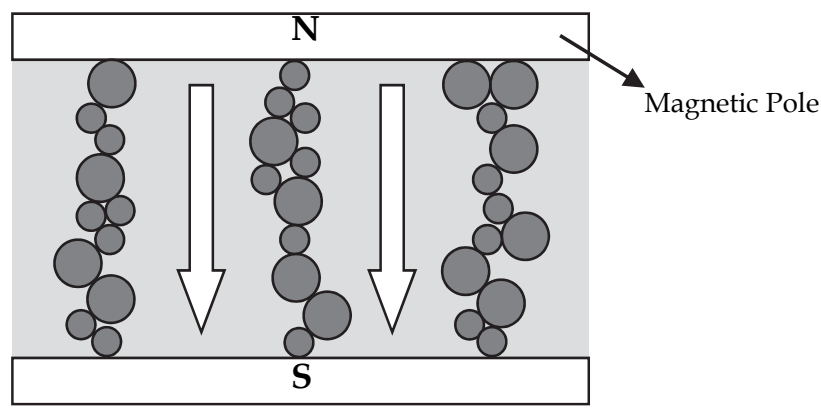

(b) magnetic field applied

Fig. 1. Phenomenological behavior of MR fluid

which is filled with nitrogen gas acts as an accumulator for absorbing sudden pressure variation of lower chamber of the MR damper induced by the rapid motion of the piston. The MR damper is divided into the upper and lower chambers by piston, and it is fully filled with the MR fluid. By the motion of the piston, the MR fluid flows through the annular duct between inner and outer piston from one chamber to the other. The magnetic poles in the piston head is placed to control the yield stress of the MR fluid by supplying current to the coil. In order effectively to generate the magnetic field in the magnetic pole, the outer cylinder and both ends of inner piston are made of ferromagnetic substance, while the center of the inner piston is a paramagnetic substance. In the absence of a magnetic field, the MR damper produces a damping force caused only by fluid viscous resistance. However, if a certain level of magnetic field is supplied to the MR damper, the MR damper produces an additional damping force owing to the yield stress of the MR fluid. This damping force of the MR damper can be continuously tuned by controlling the intensity of the magnetic field.

In order to simplify the analysis of the MR damper, it is assumed that the MR fluid is incompressible and that pressure in one chamber is uniformly distributed. The pressure drops due to the geometric shape of the annular duct and the fluid inertia are assumed to be negligible. For laminar flow in the annular duct, the fluid resistance is given by (Liu et al., 2006; White, 1994)

$$
R_{e}=8 \eta \frac{L}{\pi\left[R_{O}^{4}-R_{i}^{4}-\frac{\left(R_{o}^{2}-R_{i}^{2}\right)^{2}}{\ln \left(R_{O} / R_{i}\right)}\right]}
$$




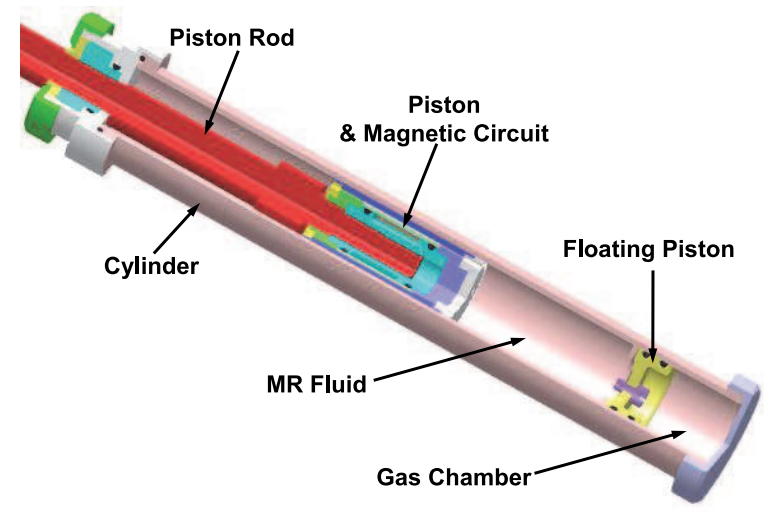

(a) MR damper

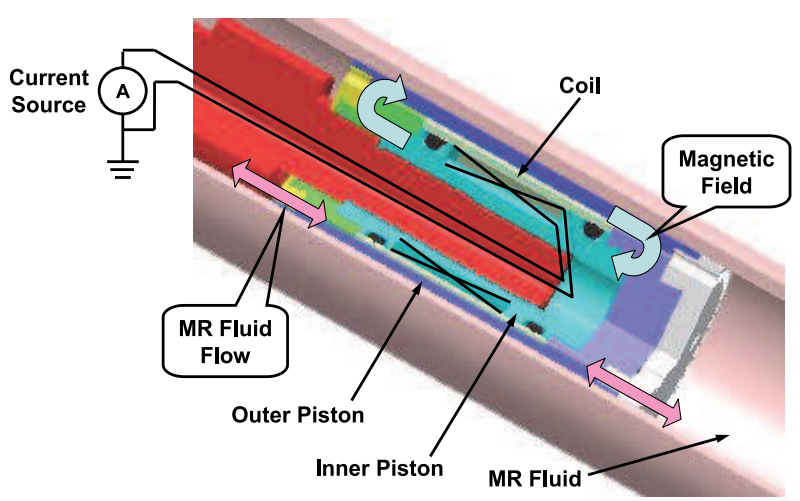

(b) piston (3-D view)

Fig. 2. Schematic configuration of the proposed MR damper

where $\eta$ is the viscosity of the MR fluid and $L$ is the length of the annular duct. $R_{o}$ and $R_{i}$ are the inner radius of the outer piston and outer radius of the inner piston respectively. By assuming that the gas does not exchange much heat with its surroundings, and hence considering its relation as adiabatic variation, the compliance of the gas chamber is obtained by

$$
C_{g}=\frac{V_{0}}{P_{0} \kappa}
$$

where $V_{0}$ and $P_{0}$ are the initial volume and pressure of the gas chamber respectively, and $\kappa$ is the specific heat ratio. On the other hand, the pressure drop due to the increment of the yield stress of the MR fluid is given by

$$
P_{M R}=2 \frac{c L_{p}}{h} \tau_{y}(B)
$$

where $c$ is a coefficient that depends on flow velocity profile and has a value range from 2.0 to $3.0, L_{p}$ is the length of the magnetic pole, $h$ is the gap of the annular duct, and $\tau_{y}(B)$ is the 
yield stress caused by the magnetic flux density $B$. Therefore, the damping force of the proposed MR damper can be written as

$$
F_{D}=k_{e} x_{p}+c_{e} \dot{x}_{p}+F_{M R}
$$

where

\begin{tabular}{|l|l|}
\hline Parameter & Value \\
\hline Duct Length $(L)$ & $82 \mathrm{~mm}$ \\
\hline Piston Area $\left(A_{p}\right)$ & $1661.90 \mathrm{~mm}^{2}$ \\
\hline Piston Rod Area $\left(A_{r}\right)$ & $380.13 \mathrm{~mm}^{2}$ \\
\hline Duct Width $(b)$ & $123.53 \mathrm{~mm}$ \\
\hline Maximum Stroke & $164 \mathrm{~mm}$ \\
\hline
\end{tabular}

Table 1. Design parameters of the MR damper

$$
\begin{gathered}
k_{e}=\frac{A_{r}^{2}}{C_{g}}, \quad c_{e}=\left(A_{p}-A_{r}\right)^{2} R_{e} \\
F_{M R}=\left(A_{p}-A_{r}\right) P_{M R} \operatorname{sgn}\left(\dot{x}_{p}\right)
\end{gathered}
$$

where $x_{p}$ and $\dot{x}_{p}$ are the piston displacement and velocity respectively, $A_{p}$ and $A_{r}$ represent the piston and piston rod areas respectively, and $\operatorname{sgn}(\cdot)$ is a signum function.

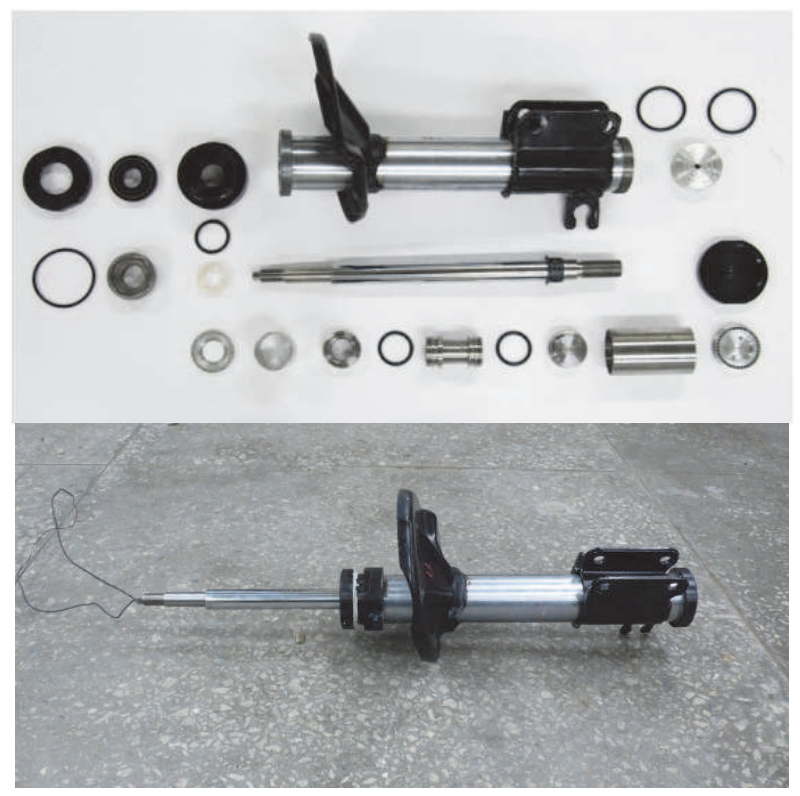

Fig. 3. Photograph of the manufactured MR damper

The photograph of the manufactured MR damper with optimally obtained design parameters are shown in Fig. 3. The principal design parameters of the manufactured MR damper, which can be applied to a mid-sized commercial passenger vehicle, are presented 
in Table 1. Fig. 4 presents the measured and analysed damping force $F_{D}$ characteristics of the MR damper with respect to the piston velocity at various magnetic fields. This is obtained by calculating the maximum damping force at each velocity. The piston velocity is changed by increasing the excitation frequency from 0.5 to $4.0 \mathrm{~Hz}$, while the excitation amplitude is kept constant $\pm 20 \mathrm{~mm}$. This type of plot is frequently used in the damper manufacturing industry to evaluate the level of damping performance. It is clearly observed that the damping force is increased as the magnetic field increases, as expected. The damping force response of the MR damper is measured as shown in Fig. 5. It can be found that the time constant is about $23 \mathrm{~ms}$, which is obtained by inspecting the required time when the damping force reaches 63.2percent of its final steady state value.

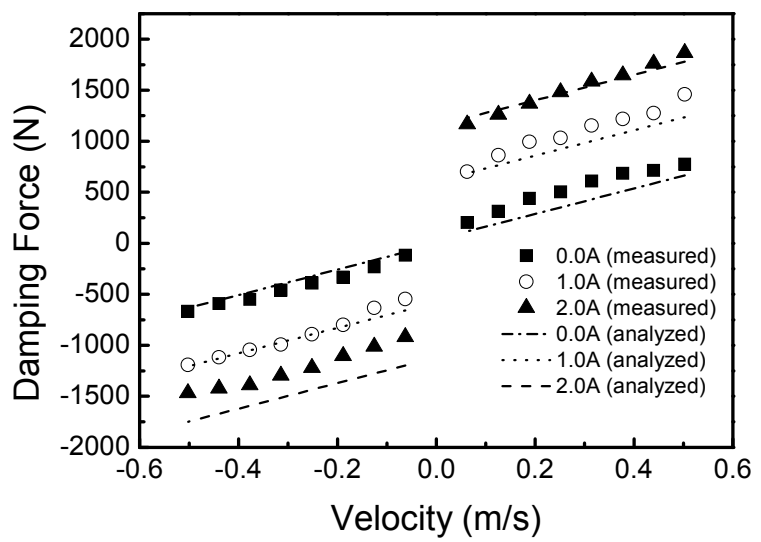

Fig. 4. Field-dependent damping force of the MR damper

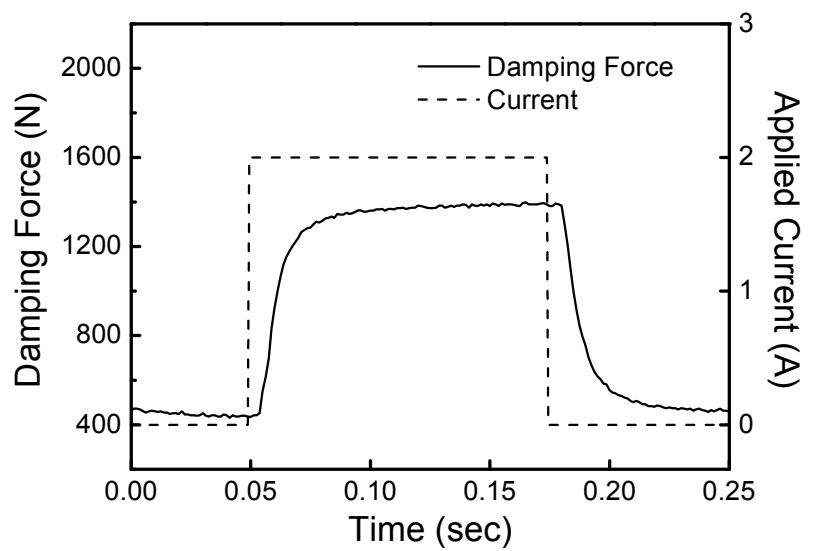

Fig. 5. Damping force responses of the MR damper 


\subsection{Quarter vehicle MR suspension}

In order to investigate the effectiveness of vibration control algorithm, a quarter vehicle MR suspension system is constructed as shown in Fig. 6. It shows that the proposed quarter vehicle suspension model with the MR damper has two degrees of freedom. The spring for the suspension is assumed to be linear and the tire is also modelled as linear spring component. From the mechanical model, dynamic equation of system considering time constant can be expressed as follows:

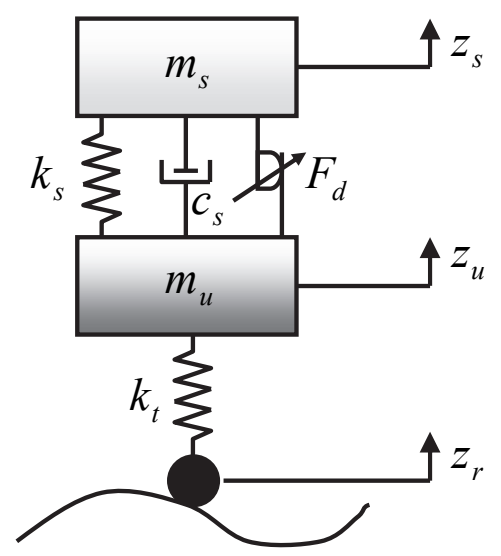

Fig. 6. Mechanical model of a quarter vehicle MR suspension system

$$
\begin{gathered}
m_{s} \ddot{z}_{s}=-k_{s} z_{s}-c_{s} \dot{z}_{s}+k_{s} z_{u}+c_{s} \dot{z}_{u}-F_{M R} \\
m_{u} \ddot{z}_{u}=k_{s} z_{s}+c_{s} \dot{z}_{s}-\left(k_{t}+k_{s}\right) z_{u}-c_{s} \dot{z}_{u}+F_{M R}+k_{t} z_{r} \\
\dot{F}_{M R}=-\frac{1}{\tau_{M R D}} F_{M R}+\frac{1}{\tau_{M R D}} u
\end{gathered}
$$

\begin{tabular}{|c|c|}
\hline Parameter & Value \\
\hline Sprung Mass $\left(m_{s}\right)$ & $373.5 \mathrm{~kg}$ \\
\hline Unsprung Mass $\left(m_{u}\right)$ & $40 \mathrm{~kg}$ \\
\hline Stiffness Coefficient $\left(k_{s}\right)$ & $27358 \mathrm{~N} / \mathrm{m}$ \\
\hline Tire Stiffness Coefficient $\left(k_{t}\right)$ & $211625 \mathrm{~N} / \mathrm{m}$ \\
\hline Damping Coefficient $\left(c_{s}\right)$ & $570 \mathrm{Ns} / \mathrm{m}$ \\
\hline
\end{tabular}

Table 2. System parameters of the quarter vehicle suspension system

where $\tau_{M R D}$ is time constant of the MR damper, $k_{s}$ is the total stiffness coefficient of the suspension, including the effective stiffness $k_{e}$ of the MR damper in equation (4), $c_{s}$ is the damping coefficient of the suspension and is assumed to be equal to $c_{e}, k_{t}$ is the vertical stiffness of the tire, and $z_{s}, z_{u}$ and $z_{r}$ are the vertical displacements of sprung mass, unsprung mass and road excitation respectively. The state space equation of proposed quarter vehicle suspension can be expressed using dynamic equation (Lee et al., 2011):

$$
\dot{\boldsymbol{x}}=\boldsymbol{A} \boldsymbol{x}+\boldsymbol{B} u+L z_{r}, \quad y=C x
$$


where

$$
\begin{gathered}
\boldsymbol{A}=\left[\begin{array}{lllll}
z_{s} & \dot{z}_{s} & z_{u} & \dot{z}_{u} & F_{M R}
\end{array}\right]^{T} \\
\boldsymbol{A}=\left[\begin{array}{ccccc}
0 & 1 & 0 & 0 & 0 \\
k_{s} / m_{s} & -c_{s} / m_{s} & k_{s} / m_{s} & c_{s} / m_{s} & -1 / m_{s} \\
0 & 0 & 0 & 1 & 0 \\
k_{s} / m_{u} & c_{s} / m_{u} & -\left(k_{t}+k_{s}\right) / m_{u} & -c_{s} / m_{u} & 1 / m_{u} \\
0 & 0 & 0 & 0 & -1 / \tau_{M R D}
\end{array}\right], \\
\boldsymbol{B}=\left[\begin{array}{lllllll}
0 & 0 & 0 & 0 & 1 / \tau_{M R D}
\end{array}\right]^{T}, \boldsymbol{L}=\left[\begin{array}{lllll}
0 & 0 & 0 & k_{t} / m_{u} & 0
\end{array}\right]^{T}, \\
\boldsymbol{C}=\left[\begin{array}{llllll}
1 & 0 & 0 & 0 & 0
\end{array}\right]
\end{gathered}
$$

The system parameters of the quarter vehicle MR suspension system are chosen on the basis of the conventional suspension system for a mid-sized passenger vehicle, and listed in Table 2.

\section{Control strategies}

In order to evaluate vibration control performance of the quarter vehicle MR suspension system, various control strategies are formulated and experimentally implemented.

\subsection{Skyhook controller}

Skyhook controller is simple but very effective control algorithm. It is well known that the logic of the skyhook controller is easy to implement in the real field. The principle of skyhook control is to design the active or semiactive suspension control so that the sprung mass is linked to the sky in order to reduce the vertical oscillations of the sprung mass. Fig. 7 shows the conceptual scheme of skyhook controller for vehicle suspension system. The desired damping force is set by

$$
u=C_{s k y} \dot{z}_{s}
$$

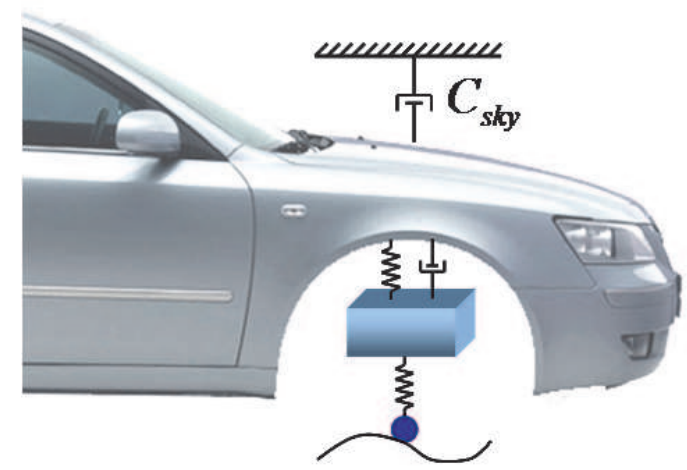

Fig. 7. Scheme of the skyhook controller for vehicle suspension system 
where $C_{\text {sky }}$ is the control gain, which physically indicates the damping coefficient. In this work, the value is chosen as 2470 using trial-and-error method.

\subsection{LQG controller}

Optimal control of a linear system with respect to the quadratic objective function under incomplete measurements corrupted by white Gaussian noise is generally referred to as the linear quadratic Gaussian (LQG) problem. The optimal control is a linear function of the state estimates obtained from the Kalman-Bucy filter. The LQR (linear quadratic regulation) is a state feedback problem, whereas LQG is an output feedback problem, which is more realistic (Bahram \& Michael, 1993). Fig. 8 shows the block diagram of an LQG controller. In this study, the control input is formulated as follows:

$$
\mathrm{u}=-K_{L Q G} \widehat{\boldsymbol{x}}
$$

where $\widehat{\boldsymbol{x}}$ is the estimated state. Control gain $K_{L Q G}$ is set as

$\left[\begin{array}{lllll}-1248.3 & 1150.3 & -4121.8 & 15.5 & 0.4\end{array}\right]$ in this work.

\section{$3.3 \mathrm{H}_{\infty}$ controller}

In reality, the sprung mass of the vehicle is varied by the loading conditions such as the number of riding persons and payload. And it makes the pitch and roll mass moment of inertia to be changed. Therefore, in order to successfully control the vibration, a robust control algorithm is required by considering the parameter variations of the system. From the structured suspension model, a desirable damping force required to effectively suppress the vibration is determined by adopting $\mathrm{H}_{\infty}$ controller. Fig. 9 shows the nominal plant, perturbed plant, shaped plant and loop gain graph. As shown in Fig., loop gain and perturbed plant are well matched and it means loop perturbation is successfully constructed.

For reducing the steady state error and suppressing the effectiveness of disturbance, weighting function can be designed as follows (Choi et al., 1999; 2002):

$$
\mathrm{W}=180 \frac{s+88}{s}
$$

For the design of controller, design index $\gamma$ is set as 2.99. Fig. 10 shows the sensitivity and complementary sensitivity of the closed loop system. Therefore, control gain can be calculated as follows:

$$
\mathrm{u}=K_{H \infty} \boldsymbol{x}, K_{H \infty}=\frac{N(s)}{D(s)}
$$

where $N(s)=-1.45 e 2 s^{6}-2.29 e 4 s^{5}-1.82 e 6 s^{4}-1.12 e 8 s^{3}-2.10 e 9 s^{2}+5.20 e 10 s-$ 6.91e6, $D(s)=s^{7}+92.03 s^{6}+8.34 e 3 s^{5}+3.83 e 5 s^{4}+3.47 e 6 s^{3}+3.48 e 7 s^{2}+7.51 e 2 s$.

\subsection{Sliding mode controller (SMC)}

Fig. 11 shows the conceptual scheme of sliding mode control algorithm. After the initial reaching phase, the system states slides along the sliding surface. The first step to formulate the SMC is to design a stable sliding surface. The stable sliding surface for the control system is defined as follows:

$$
\mathrm{s}=c_{1} x_{1}+c_{2} x_{2}+c_{3} x_{3}+c_{4} x_{4}+x_{5}
$$




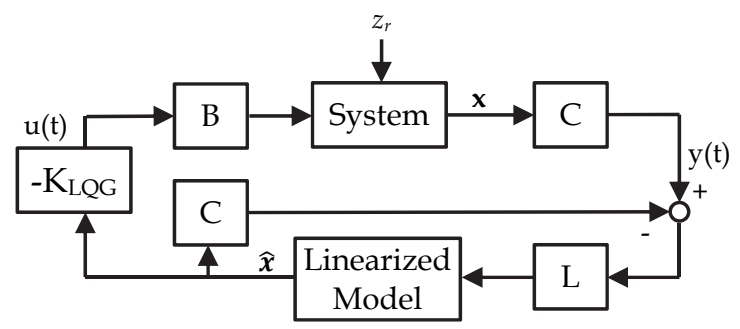

Fig. 8. Block diagram of LQG controller

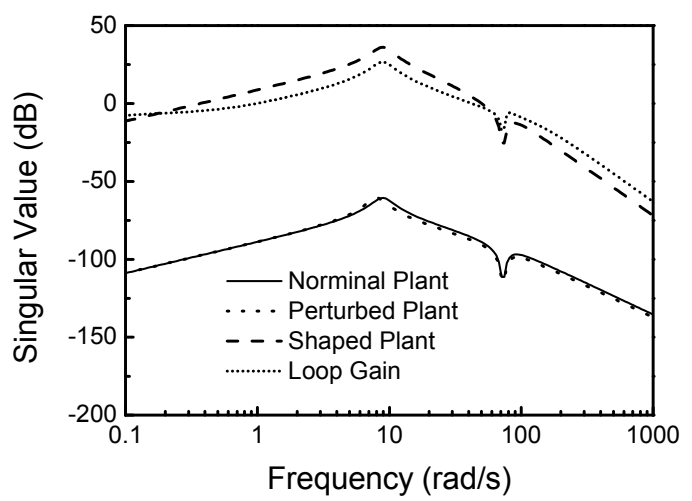

Fig. 9. Singular value plots of the quarter vehicle MR suspension system

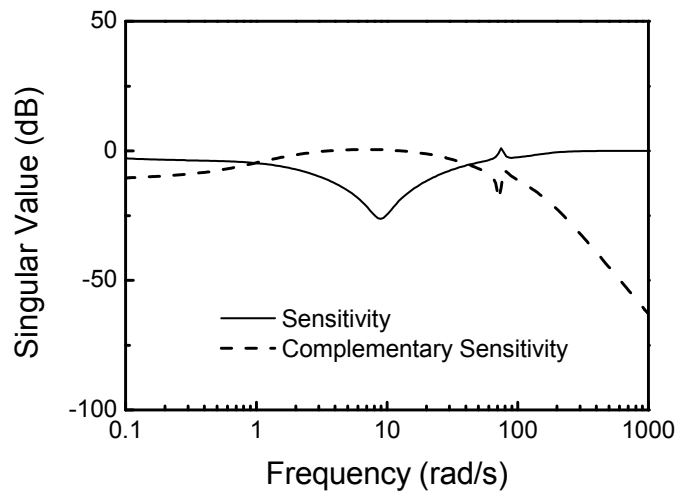

Fig. 10. Frequency domain indicators of the quarter vehicle MR suspension system 


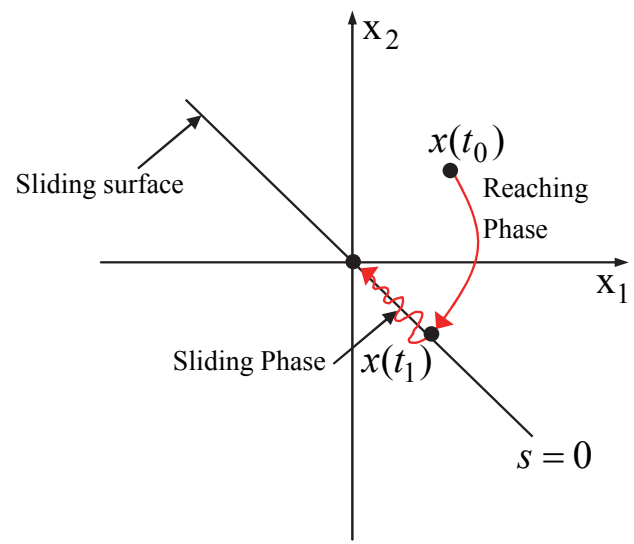

Fig. 11. Scheme of the sliding mode control

where $c_{i}(i=1,2,3,4)$ are sliding surface coefficients to be determined so that the sliding surface is stable. Then the sliding mode controller can be formulated which satisfies sliding mode condition $s \dot{s}<0$ as follows (Choi et al., 2000):

$$
\begin{gathered}
\mathrm{u}=-\frac{\tau_{M R D}}{c_{5}}\left(c_{1} x_{2}+\frac{c_{2}}{m_{s}}\left(-k_{s} x_{1}-c_{s} x_{2}+k_{s} x_{3}+c_{s} x_{4}-x_{5}\right)+c_{3} x_{4}+\frac{c_{4}}{m_{u}}\left(k_{s} x_{1}+c_{s} x_{2}-\right.\right. \\
\left.\left.\left(k_{t}+k_{s}\right) x_{3}-c_{s} x_{4}+x_{5}\right)+\frac{1}{\tau_{M R D}} x_{5}\right)-k s g n(s),(k>0)
\end{gathered}
$$

where $k$ stands for the discontinuous gain which is a positive number. The discrete gain can be changed to continuous gain for reducing the chattering problem.

$$
\operatorname{sat}(s)=\left\{\begin{array}{cc}
s / \varepsilon & \text { for }|s / \varepsilon| \leq 1 \\
\operatorname{sgn}(s) & \text { for }|s / \varepsilon|>1
\end{array}\right.
$$

\subsection{Moving sliding mode controller (MSMC)}

It is required to reduce reaching phase to improve the performance and robustness of the SMC. Reaching time can be successfully reduced in case that sliding surface is rotated or shifted by considering reaching phase. Fig. 12 illustrates two moving patterns of the sliding surface: rotating and shifting. The sliding surface for moving sliding mode controller can be determined as follows:

$$
\begin{gathered}
\mathrm{s}=c_{1}\left(x_{1}, x_{2}\right) x_{1}+c_{2} x_{2}+c_{3} x_{3}+c_{4} x_{4}+x_{5}+\alpha\left(x_{1}, x_{2}\right) \\
c_{1}\left(x_{1}, x_{2}\right)=\frac{\left(\Delta_{f r}-x_{2}\right)}{x_{1}}, \alpha\left(x_{1}, x_{2}\right)=c_{10} x_{1}+x_{2}-\Delta_{f s}
\end{gathered}
$$

where $\Delta_{f r}$ and $\Delta_{f s}$ are gain for surface rotating and surface shifting respectively. $c_{1 o}$ is initial value of $c_{1}$. The moving sliding mode controller can be formulated as follows:

$$
\begin{aligned}
& \mathrm{u}=-\frac{\tau_{M R D}}{c_{5}}\left(c_{1}\left(x_{1}, x_{2}\right) x_{2}+\frac{c_{2}}{m_{s}}\left(-k_{s} x_{1}-c_{s} x_{2}+k_{s} x_{3}+c_{s} x_{4}-x_{5}\right)+c_{3} x_{4}+\frac{c_{4}}{m_{u}}\left(k_{s} x_{1}+c_{s} x_{2}-\right.\right. \\
& \left.\left.\left(k_{t}+k_{s}\right) x_{3}-c_{s} x_{4}+x_{5}\right)+\frac{1}{\tau_{M R D}} x_{5}+\alpha\left(x_{1}, x_{2}\right)\right)-k \operatorname{sgn}(s),(k>0)
\end{aligned}
$$




\subsection{Fuzzy moving sliding mode controller (FMSMC)}

The fuzzy moving sliding mode controller, which can change the coefficients and intercepts of sliding surface by fuzzy tuning which takes into account for location of reaching phase, is developed. Fig. 13 presents the block diagram of the proposed FMSMC. The basic configuration of fuzzy control consists of three components: a fuzzification interface, a decision-making logic and a deffuzification interface. In this study, the coefficient of sprung mass displacement $x_{1}$ is considered with priority while other coefficients of sliding surface are fixed. Rotating algorithm, which can change the sliding surface $c_{1}$ as a function of $x_{1}$, is applied to reduce the reaching phase. However, it is hard to expect that the robustness is enhanced in case that initial condition of reaching phase is located in quadrant 1 or quadrant 3. Hence, shifting algorithm, which can change the intercept $\alpha$ as a function of $x_{1}$, is adopted and determined according to the relative place of sliding surface, and this will sufficiently reduce the reaching phase. Therefore, the sliding surface can be written as follows (Cho et al., 2007):

$$
\mathrm{s}=c_{1}\left(x_{1}\right) x_{1}+c_{2} x_{2}+c_{3} x_{3}+c_{4} x_{4}+\alpha\left(x_{1}\right)
$$

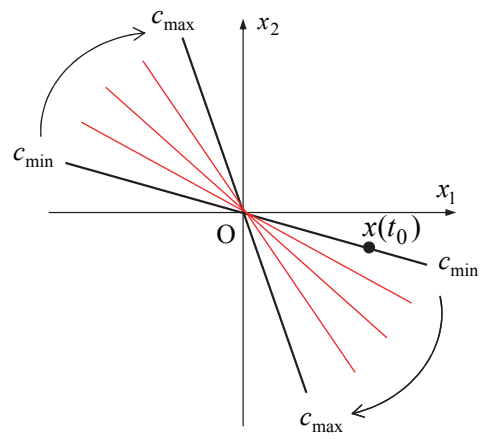

(a) rotating sliding surface

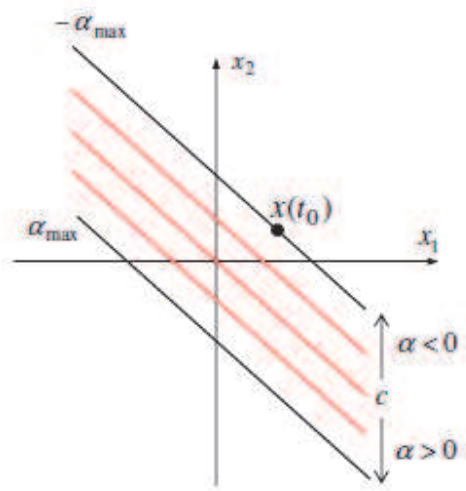

(b) shifting sliding surface

Fig. 12. Scheme of the moving sliding mode control 


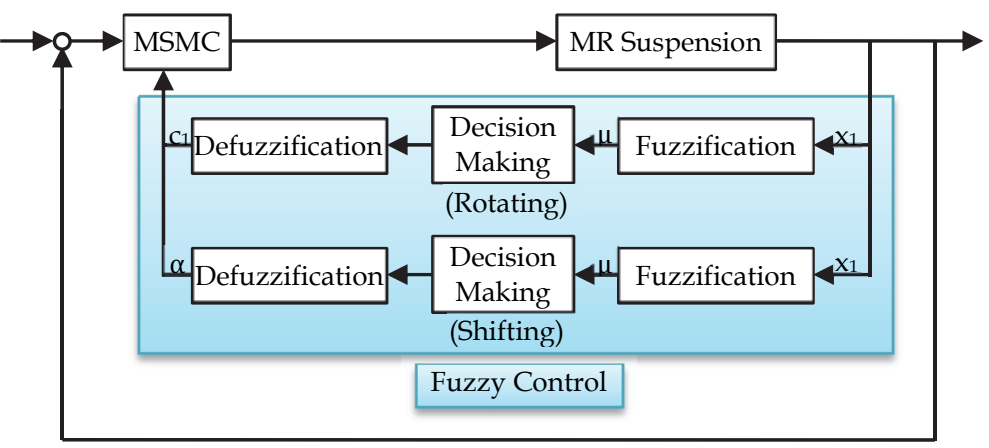

Fig. 13. Block-diagram of the proposed FMSMC

where $c_{1}$ and $\alpha$ are determined by tuning of fuzzy logic which takes into account for displacement and direction of sprung mass displacement of $x_{1}$. In this case, the sliding surface should maintain stability, although $c_{1}$ and $\alpha$ are changed according to time. In order to reduce reaching time in the rotating algorithm, $c_{1}$ should be high in case of the opposite case. In the letter case, the sprung displacement $x_{1}$ can be converted toward 0 more quickly. In the shifting control algorithm, absolute value of $\alpha$ should be high in case that absolute value of $x_{1}$ is large and vice versa. Furthermore, sliding surface is moved upward for positive $x_{1}$ and sliding surface is moved downward for the opposite case. Consequently, we can formulate the following control input of the proposed FMSMC, which is combined rotating and shifting algorithm:

$$
\begin{aligned}
& \mathrm{u}=-\frac{\tau_{M R D}}{c_{5}}\left\{\left(c_{1}\left(x_{1}\right)+\frac{\Delta c_{1} \chi_{1 r} \sinh \left(\chi_{1 r}\right)}{\cosh ^{2}\left(\chi_{1 r}\right)}-\frac{\left(\alpha_{\max } / \sigma_{s}\right)}{\cosh ^{2}\left(\chi_{1 s}\right)}\right) x_{2}+\frac{c_{2}}{m_{s}}\left(-k_{s} x_{1}-c_{s} x_{2}+k_{s} x_{3}+c_{s} x_{4}-x_{5}\right)+\right. \\
& \left.c_{3} x_{4}+\frac{c_{4}}{m_{u}}\left(k_{s} x_{1}+c_{s} x_{2}-\left(k_{t}+k_{s}\right) x_{3}-c_{s} x_{4}+x_{5}\right)-\frac{1}{\tau_{M R D}} x_{5}\right\}-k \operatorname{sgn}(s),(k>0)
\end{aligned}
$$

The control input determined from the FMSMC is to be applied to the MR damper depending upon the motion of suspension travel. The detailed control algorithm was described by Cho et al., 2007.

\subsection{Semi-active condition}

The control input $\mathrm{u}$ directly represents the damping force of $F_{M R}$. On the other hand, the damping of the suspension system needs to be controlled depending upon the motion of suspension travel. Therefore, the following semi-active actuating condition is imposed:

$$
\mathrm{u}= \begin{cases}u & \text { for } u\left(\dot{z}_{s}-\dot{z}_{u}\right)>0 \\ 0 & \text { for } u\left(\dot{z}_{s}-\dot{z}_{u}\right) \leq 0\end{cases}
$$

This semi-active condition can assure the increment of damping characteristic of the suspension system and hence increase the stability of the system.

\section{Control performances}

Vibration control performances of the quarter vehicle MR suspension system are evaluated under two types of excitation (road) conditions. The first excitation, normally used to reveal the transient response characteristic, is a bump described by 


$$
z_{r}=A_{m}[1-\cos (\omega t)]
$$

where $\omega=2 \pi f, f=1 / T$ and $T=D / V . A_{m}(=0.07 \mathrm{~m})$ is the bump height, $D(=0.8 \mathrm{~m})$ is the width of the bump and $V$ is the vehicle velocity. In the bump excitation, the vehicle travels the bump with a constant vehicle velocity of $3.08 \mathrm{~km} / \mathrm{h}(=0.856 \mathrm{~m} / \mathrm{s})$. The second excitation is a random road conditions.

Fig. 14 shows the experimental apparatus of the quarter vehicle MR suspension system to evaluate and compare the effectiveness of vibration isolation of the proposed control algorithms. The MR suspension (assembly of the MR damper and spring), sprung mass and tire are installed on the hydraulic excitation system. The sprung mass displacement and excitation displacement are measured by LVDT (linear variable differential transformer) and the suspension travel is measured by a wire sensor. The hydraulic system applies the road profile to the MR suspension system. The current amplifier applies the control current determined from the control algorithm to the MR damper.

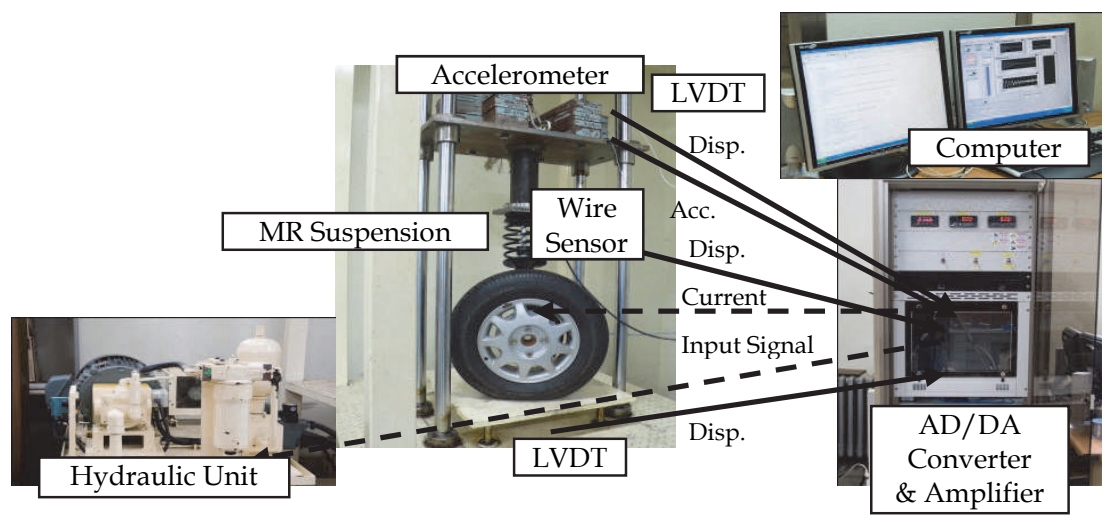

Fig. 14. Experimental apparatus of the quarter vehicle MR suspension system

Fig. 15 presents vertical displacement, vertical acceleration of sprung mass and suspension travel versus time responses of the MR suspension system for the bump excitation. As shown in the Fig., it can obviously be found that unwanted vibrations induced from the bump excitation are well suppressed by adopting the control algorithms in the MR suspension system. Fig. 16 shows the performance comparison of vertical acceleration RMS of the quarter vehicle MR suspension system for the bump excitation. The RMS value is calculated from:

$$
R M S=\sqrt{\frac{x_{1}^{2}+x_{2}^{2}+\cdots+x_{n}^{2}}{n}}
$$

As shown in Fig., skyhook control algorithm shows quite good vibration control performance. Also, Fig. 17 shows the PSD (power spectrum density) of sprung mass acceleration in frequency domain for the random excitation and Fig. 18 shows the performance comparison of vertical acceleration RMS of the quarter vehicle MR suspension system for the random excitation. As expected, the PSD of the vertical acceleration has been 

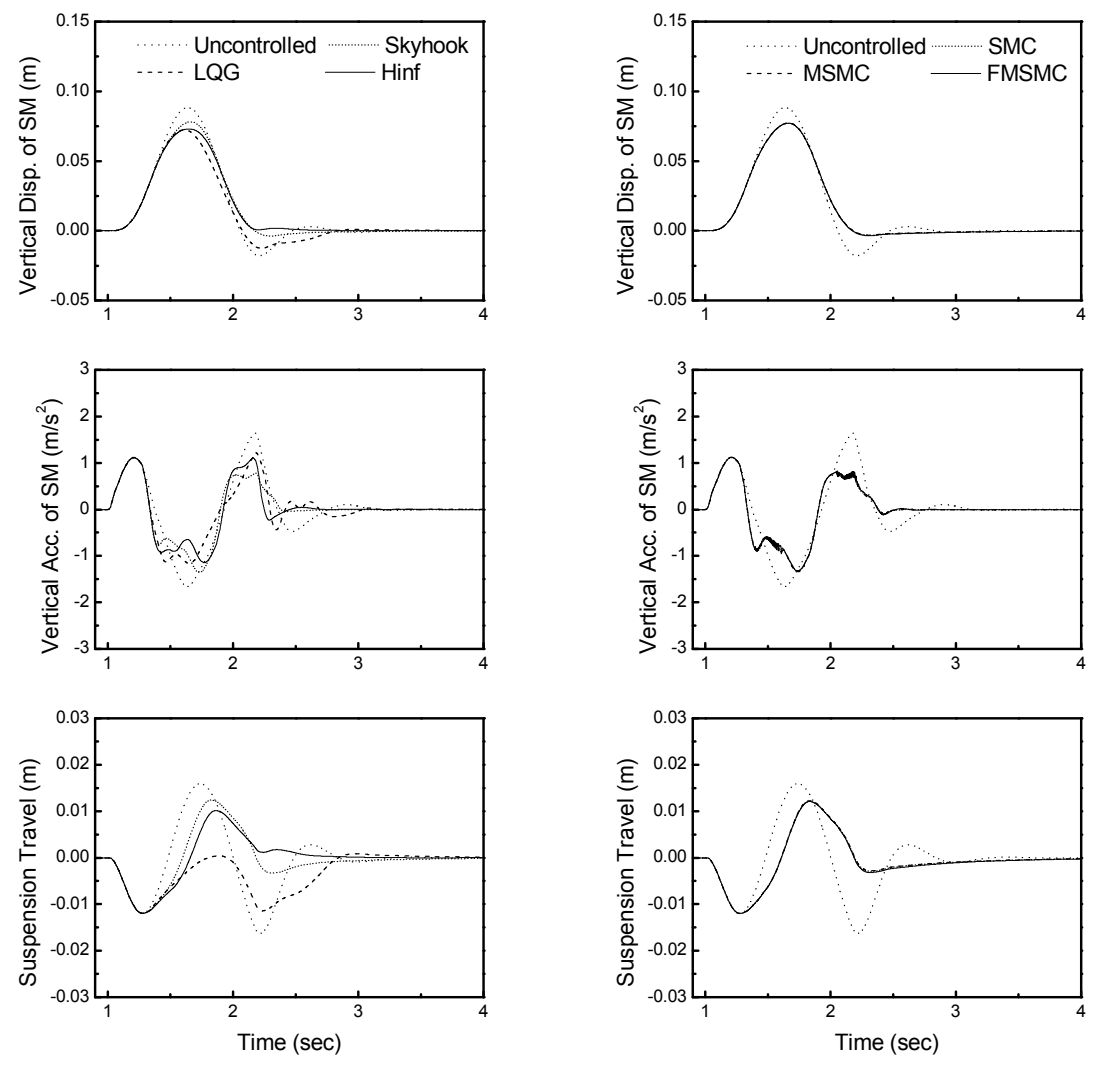

Fig. 15. Bump responses of the quarter vehicle MR suspension system

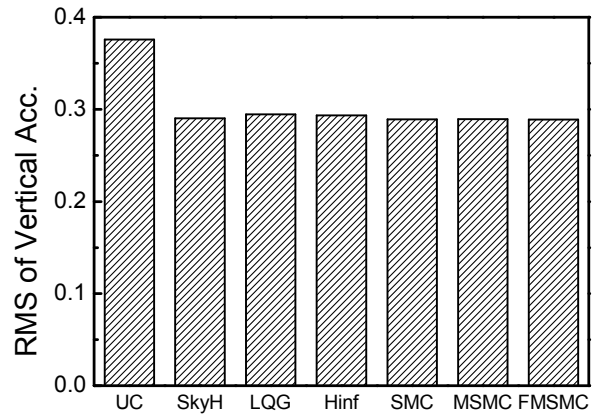

Fig. 16. Performance comparison of vertical acceleration RMS of the quarter vehicle MR suspension system (bump) 

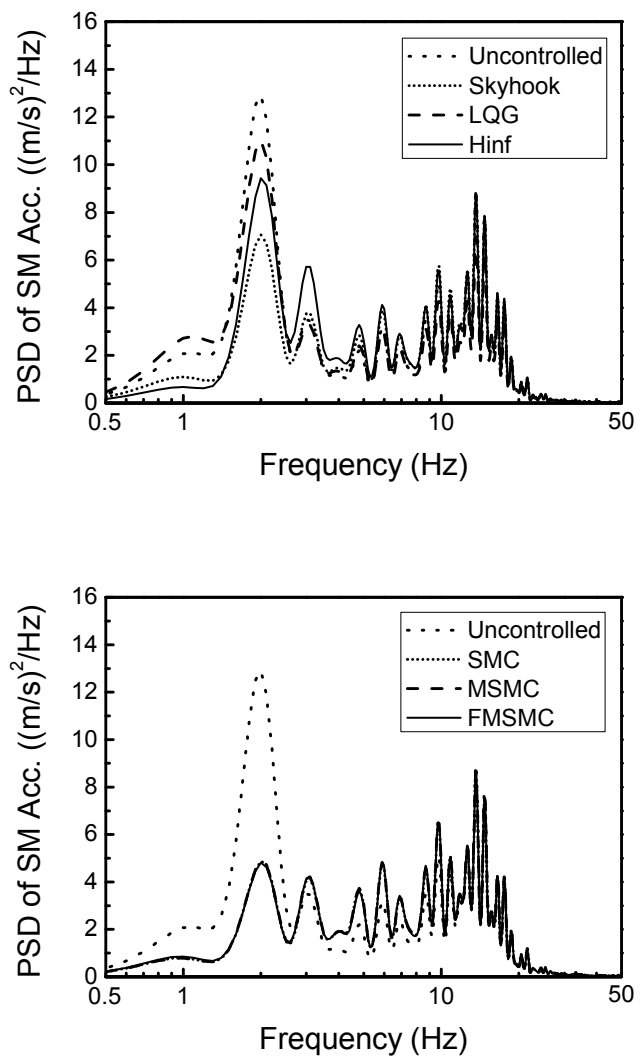

Fig. 17. Random responses of the quarter vehicle MR suspension system $(72 \mathrm{~km} / \mathrm{h})$

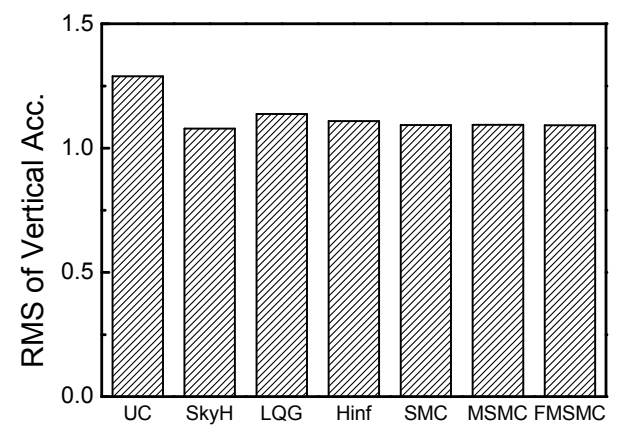

Fig. 18. Performance comparison of vertical acceleration RMS of the quarter vehicle MR suspension system (random, $72 \mathrm{~km} / \mathrm{h}$ ) 
considerably reduced in the neighbourhood of body resonance $(1 \sim 2 \mathrm{~Hz})$ by applying control input. The control results presented in Figs. 15 18 indicate that ride comfort of a vehicle system can be substantially improved by employing the MR suspension system associated with the proposed control algorithms.

\section{Conclusion}

In this chapter, control algorithms for vibration control of the quarter vehicle MR suspension system were proposed and its effectiveness was experimentally verified and compared. In order to achieve this goal, a cylindrical MR damper was designed and manufactured. After evaluating the field-dependent damping characteristics of the MR damper, a quarter vehicle suspension system was then constructed and its governing equations of motion were derived. In order to obtain a favourable control performance of the MR suspension system, skyhook controller, LQG controller, $\mathrm{H}_{\infty}$ controller, sliding mode controller, moving sliding mode controller and fuzzy moving sliding mode controller were designed and experimentally realized to the quarter vehicle MR suspension system. It has been experimentally shown that the proposed control algorithms can reduce the unwanted vibration under bump excitation. In addition, it has been demonstrated that using the proposed control methodologies vibration levels such as sprung mass acceleration under random excitation can be significantly reduced at body resonance region. The results presented here are self-explanatory justifying that the control strategies implemented in this work can produce very similar vibration control performance. This directly indicates that ride comfort of the vehicle system can be substantially improved by adopting the MR suspension system associated with the proposed control strategies.

\section{References}

Bahram, S. and Michael, H. (1993). Control System Design Using MATLAB, Prentice Hall, ISBN 0-13-174061-X, New Jersey

Carlson, J. D., Cantanzarite, D. M. and St.Clair, K. A. (1996). Commercial Magnetorheological Fluid Devices. Electro-Rheological Fluids, Magneto-Rheological Suspensions and Associated Technology, Vol.1996, pp. 20-28, ISBN 981-02-2676-4

Cho, J. W., Pang, Y. S., Choi, S. B. and Kim, K. S. (2007). Fuzzy Moving Sliding Mode Control of Vehicle Suspension Featuring ER Shock Absorber. International Conference on Electro-Rheological Fluids and Magneto-Rheological Suspensions, ISBN 978-981-2771-19-3, Lake Tahoe, USA

Choi, S. B., Han, S. S., Kim, H. K. and Cheong, C. C. (1999). $\mathrm{H}_{\infty}$ Control of a Flexible Gantry Robot Arm Using Smart Actuators. Mechatronics: Mechanics, Electronics, Control, Vol.9, No.3, pp. 271-286, ISSN 0957-4158

Choi, S. B., Choi, Y. T. and Park, D. W. (2000). A Sliding Mode Control of a Full-Car Electrorheological Suspension System Via Hardware in-the-Loop Simulation. Journal of Dynamic Systems, Measurement, and Control, Vol.122, No.1, pp. 114-121, ISSN 0022-0434

Choi, S. B., Lee, S. K. and Park, Y. P. (2001). A Hysteresis Model for the Field-Dependent Damping Force of a Magnetorheological Damper. Journal of Sound and Vibration, Vol.245, No.2, pp. 375-383, ISSN 0022-460x 
Choi, S. B., Lee, H. S. and Park, Y. P. (2002). $\mathrm{H}_{\infty}$ Control Performance of a Full-Vehicle Suspension Featuring Magnetorheological Dampers. Vehicle System Dynamics, Vol.38, No.5, pp. 341-360, ISSN 0042-3114

Du, H., Yim, S. K. and Lam, J. (2005). Semi-Active $\mathrm{H}_{\infty}$ Control of Vehicle Suspension with Magneto-Rheological Dampers. Journal of Sound and Vibration, Vol.283, No.3/5, pp. 981-996, ISSN 0022-460x

Guo, D. and Hu, H. (2005). Nonlinear Stiffness of a Magneto-Rheological Damper. Nonlinear Dynamics, Vol.40, No.3, pp. 241-249, ISSN 0924-090x

Hong, S. R., Wereley, N. M., Choi, Y. T. and Choi, S. B. (2008). Analytical and Experimental Validation of a Nondimensional Bingham Model for Mixed-Mode Magnetorheological Dampers. Journal of Sound and Vibration, Vol.312, No.3, pp. 399417, ISSN 0022-460x

Kamath, G. M., Wereley, N. M. and Jolly, M. R. (1998). Characterization of Semiactive Magnetorheological Helicopter Lag Mode Dampers. Smart Structures and Integrated Systems, Vol.1998, pp. 356-377, ISSN 0277-786x

Kim, J. H., Kang, B. W., Park, K. M., Choi, S. B. and Kim, K. S. (2002). MR Inserts For Shock Wave Reduction in Warship Structures. Journal of Intelligent Material Systems and Structures, Vol.13, No.10, pp. 661-666, ISSN 1045-389x

Lee, H. G., Sung, K. G., Choi, S. B., Park, M. K. and Park, M. K. (2011). Performance Evaluation of a Quarter-Vehicle MR Suspension System with Different Tire Pressure. International Journal of Precision Engineering and Manufacturing, Vol.12, No.2, pp. 203-210, ISSN 1229-8557

Liu, B., Li, W. H., Kosasih, P. B. and Zhang, X. Z. (2006). Development of an MR-BrakeBased Haptic Device. Smart Materials and Structures, Vol.15, No.6, pp. 1960-1966, ISSN 0964-1726

Ok, S. Y., Kim, D. S., Park, K. S. and Koh, H. M. (2007). Semi-Active Fuzzy Control of CableStayed Bridges Using Magneto-Rheological Dampers. Engineering Structures, Vol.29, No.5, pp. 776-788, ISSN 0141-0296

Pranoto, T. and Nagaya, K. (2005). Development on 2DOF-Type and Rotary-Type Shock Absorber Damper Using MRF and Their Efficiencies. Journal of Materials Processing Technology, Vol.161, No.1/2, pp. 146-150, ISSN 0924-0136

Seong, M. S., Choi, S. B. and Han, Y. M. (2009). Damping Force Control of a Vehicle MR Damper Using a Preisach Hysteretic Compensator. Smart Materials and Structures, Vol.18, No.7, pp. 1-13, ISSN 0964-1726

Shen, Y., Golnaraghi, M. F. and Heppler, G. R. (2007). Load-Leveling Suspension System with a Magnetorheological Damper. Vehicle System Dynamics, Vol.45, No.4, pp. 297312, ISSN 0042-3114

Spencer Jr., B. F., Dyke, S. J., Sain, M. K. and Carlson, J. D. (1997). Phenomenological Model for Magnetorheological Dampers. Journal of Engineering Mechanics, Vol.123, No. 3, pp. 230-238, ISSN 0733-9399

White, F. M. (2003). Fluid Mechanics (Fifth Edition), Mcgraw-Hill, ISBN 0-07-240217-2, New York

Yu, M., Liao, C. R., Chen, W. M. and Huang, S. L. (2006). Study on MR Semi-Active Suspension System and its Road Testing. Journal of Intelligent Material Systems and Structures, Vol.17, No.8/9, pp. 801-806, ISSN 1045-389x

Yu, M., Dong, X. M., Choi, S. B. and Liao, C. R. (2009). Human Simulated Intelligent Control of Vehicle Suspension System with MR Dampers. Journal of Sound and Vibration, Vol.319, No.3/5, pp. 753-767, ISSN 0022-460x 


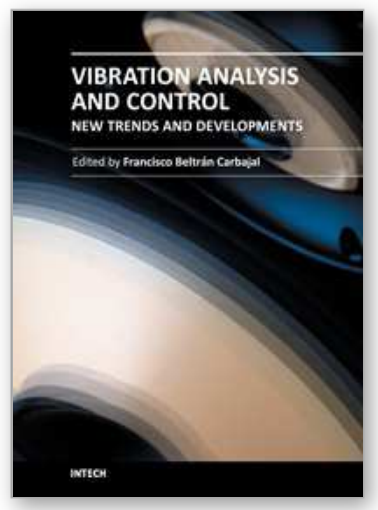

\author{
Vibration Analysis and Control - New Trends and Developments \\ Edited by Dr. Francisco Beltran-Carbajal
}

ISBN 978-953-307-433-7

Hard cover, 352 pages

Publisher InTech

Published online 06, September, 2011

Published in print edition September, 2011

This book focuses on the important and diverse field of vibration analysis and control. It is written by experts from the international scientific community and covers a wide range of research topics related to design methodologies of passive, semi-active and active vibration control schemes, vehicle suspension systems, vibration control devices, fault detection, finite element analysis and other recent applications and studies of this fascinating field of vibration analysis and control. The book is addressed to researchers and practitioners of this field, as well as undergraduate and postgraduate students and other experts and newcomers seeking more information about the state of the art, challenging open problems, innovative solution proposals and new trends and developments in this area.

\title{
How to reference
}

In order to correctly reference this scholarly work, feel free to copy and paste the following:

Min-Sang Seong, Seung-Bok Choi and Kum-Gil Sung (2011). Control Strategies for Vehicle Suspension System Featuring Magnetorheological (MR) Damper, Vibration Analysis and Control - New Trends and Developments, Dr. Francisco Beltran-Carbajal (Ed.), ISBN: 978-953-307-433-7, InTech, Available from: http://www.intechopen.com/books/vibration-analysis-and-control-new-trends-and-developments/controlstrategies-for-vehicle-suspension-system-featuring-magnetorheological-mr-damper

\section{INTECH}

open science | open minds

\author{
InTech Europe \\ University Campus STeP Ri \\ Slavka Krautzeka 83/A \\ 51000 Rijeka, Croatia \\ Phone: +385 (51) 770447 \\ Fax: +385 (51) 686166 \\ www.intechopen.com
}

\author{
InTech China \\ Unit 405, Office Block, Hotel Equatorial Shanghai \\ No.65, Yan An Road (West), Shanghai, 200040, China \\ 中国上海市延安西路65号上海国际贵都大饭店办公楼 405 单元 \\ Phone: +86-21-62489820 \\ Fax: +86-21-62489821
}


(C) 2011 The Author(s). Licensee IntechOpen. This chapter is distributed under the terms of the Creative Commons Attribution-NonCommercialShareAlike-3.0 License, which permits use, distribution and reproduction for non-commercial purposes, provided the original is properly cited and derivative works building on this content are distributed under the same license. 